\title{
Exploiting Plaintiffs Through Settlement: Divide and Conquer
}

\section{Citation}

Yeon-Koo Che \& Kathryn E. Spier, Exploiting Plaintiffs Through Settlement: Divide and Conquer, 164 J. Inst. \& Theoretical Econ. 4 (2008).

\section{Permanent link}

http://nrs.harvard.edu/urn-3:HUL.InstRepos:12019026

\section{Terms of Use}

This article was downloaded from Harvard University's DASH repository, and is made available under the terms and conditions applicable to Open Access Policy Articles, as set forth at http:// nrs.harvard.edu/urn-3:HUL.InstRepos:dash.current.terms-of-use\#OAP

\section{Share Your Story}

The Harvard community has made this article openly available.

Please share how this access benefits you. Submit a story.

\section{Accessibility}




\title{
HARVARD
}

JOHN M. OLIN CENTER FOR LAW, ECONOMICS, AND BUSINESS

\section{EXPLOITING PLAINTIFFS THROUGH SETTLEMENT: DIVIDE AND CONQUER}

\author{
Yeon-Koo Che \& Kathryn E. Spier
}

Discussion Paper No. 591

$08 / 2007$

Harvard Law School

Cambridge, MA 02138

This paper can be downloaded without charge from:

The Harvard John M. Olin Discussion Paper Series: http://www.law.harvard.edu/programs/olin_center/

The Social Science Research Network Electronic Paper Collection: $\underline{\text { http://ssrn.com/abstract=1009360 }}$ 
JEL: K4, C7, D8

\title{
Exploiting Plaintiffs Through Settlement: Divide and Conquer*
}

\author{
Yeon-Koo Che Kathryn E. SpIER
}

August 6, 2007

\begin{abstract}
This paper considers settlement negotiations between a single defendant and $N$ plaintiffs when there are fixed costs of litigation. When making simultaneous take-it-or-leave-it offers to the plaintiffs, the defendant adopts a divide and conquer strategy. Plaintiffs settle their claims for less than they are jointly worth. The problem is worse when $N$ is larger, the offers are sequential, and the plaintiffs make offers instead. Although divide and conquer strategies dilute the defendant's incentives, they increase the settlement rate and reduce litigation spending. Plaintiffs can raise their joint payoff through transfer payments, voting rules, and covenants not to accept discriminatory offers.(JEL: K4, C7, D8)
\end{abstract}

KEYWORDS: litigation, settlement, class actions, bargaining, divide and conquer, contracting with externalities

\section{Introduction}

This paper considers settlement negotiations between a single defendant and $N$ plaintiffs when there are economies of scale in litigation. In particular, litigation is assumed to involve fixed costs that will be spread among the plaintiffs who go to trial. Consequently, the decision of one plaintiff to settle out of court imposes a negative externality on the remaining plaintiffs. The defendant can easily exploit the plaintiffs in this environment, coercing the plaintiffs to settle for far less than their claims are jointly worth. This is robust to the timing of offers and the structure of information. ${ }^{1}$

*The authors thank discussants Jennifer Reinganum and Alexander Stremitzer, and many conference participants for helpful comments and lively discussion. Kathryn Spier acknowledges the financial support from the John M. Olin Center for Law, Economics, and Business at the Harvard Law School.

${ }^{1}$ But see the accompanying discussion of STREMitzer [forthcoming].

() 2007 YEON-KOO CHE \& KATHRYN E. SPIER. All Rights Reserved 
We begin by considering the case of symmetric information and identical plaintiffs. The defendant has all of the bargaining power, making simultaneous take-it-or-leave-it offers to the plaintiffs before trial. The unique coalition proof Nash equilibrium involves a divide and conquer strategy (SEGAL [2003]) where the defendant discriminates among the otherwise identical plaintiffs, making generous offers to some plaintiffs and offering less to others. When the number of plaintiffs is large, the externalities are more severe and a significant fraction of the plaintiffs receive nothing at all in equilibrium. The plaintiffs would be better off in aggregate if they coordinated their actions and made jointly optimal settlement decisions. Coordination may be achieved through a variety of mechanisms. First, the plaintiffs could raise their joint payoffs by committing ex ante to a single acceptance decision (i.e. through a unanimous voting rule). Second, the plaintiffs could achieve higher payoffs through a commitment not to accept discriminatory offers. Finally, the exchange of side payments would allow the plaintiffs to overcome the externalities and achieve a jointly optimal outcome. These mechanisms raise the plaintiffs' aggregate recovery and provide greater incentives to the defendant to take precautions to avoid accidents. ${ }^{2}$

Next, we suppose that the defendant approaches the plaintiffs in a predetermined order, making sequential take-it-or-leave-it offers to each. Interestingly, the plaintiffs may be even worse off in this scenario. When the economies of scale in litigation are sufficiently strong (or, equivalently, the number of plaintiffs sufficiently large) then the plaintiffs each receive a zero payoff. Perhaps even more surprisingly, the plaintiffs are no better off when they have the power to make take-or-leave-it offers to the defendant instead. To see why this is true, imagine that the economies of scale are sufficiently strong that a single plaintiff would never find it profitable to pursue an individual claim. The defendant can exploit the situation, accepting just $N-1$ of the offers, thereby inducing the Nth plaintiff to drop his claim. This creates a "race to the bottom" where plaintiffs make negligible settlement demands to avoid being left out of the deal.

Additional insights emerge when the plaintiffs have private information about their damages. To simplify the analysis, we restrict our attention to the case of just two plaintiffs with independently distributed damages. We first establish a benchmark where the two plaintiffs can observe each others' types and make transfer payments to each other. There are no coordination failures between the plaintiffs in this benchmark, although trials do occur in equilibrium as a result of the private information. When neither plaintiff can observe the other plaintiff's type and transfers are impossible, we show that the defendant adopts a divide and conquer strategy, making a more attractive offer to one plaintiff than the other. The defendant's aggregate payments are lower than in the case where the plaintiffs could coordinate their actions. Moreover, trials are less

\footnotetext{
${ }^{2}$ Increased incentives may or may not raise social welfare, depending on whether the defendant was overdeterred or underdeterred to begin with. See Polinsky and Rubinfeld [1988] on the deterrence effects of settlement and SHAVELL [1997] for a good discussion of the social value of litigation.
} 
likely to occur than in the benchmark case. This implies a social welfare benefit that would counterbalance to some extent any welfare loss from reduced deterrence.

Our paper is part of the broader literature on contracting with externalities (SEGAL [1999]; SEgal And Whinston [2000]). This literature studies the nature and efficiency of bilateral contracting when bilateral trade generates multilateral externalities. As described in SEGAL [2003], divide and conquer strategies naturally arise in applications such as corporate takeovers (GROSSMAN AND HART [1988]), competition among internet service providers (CAILlAUD AND JULLIEN [2003]), and exclusive contracts (INNES AND Sexton [1994]; Segal And Whinston [2000]; Rasmusen et. Al. [1991].) In the exclusive contracting setting, for example, divide and conquer strategies are socially undesirable because they can deter the entry of a more efficient supplier. In our setting, divide and conquer strategies have the social benefit of raising the settlement rate and reducing litigation costs in the presence of asymmetric information.

There is also a large literature on the settlement of litigation. Surveys of this literature include Spier [2007], DAughety [2000], and Cooter And Rubinfeld [1989]. ${ }^{3}$ While much of this literature focuses on situations involving a single plaintiff and a single defendant, others have explored strategic issues that arise when there are multiple interested parties. Take, for example, the situation where several defendants are implicated in a single plaintiff's damages. Under joint and several liability, a single losing defendant can be held personally responsible for the entire level of the plaintiff's damages. Kornhauser AND REVESZ [1994a, 1994b] show that the settlement externalities hinge on both the legal treatment of prior settlements and on the degree of correlation between the defendant's cases. ${ }^{4}$ SPIER [2002] considers the related problem of a single defendant negotiating with several plaintiffs when the defendant's wealth is insufficient to cover the damages should all plaintiffs win at trial. CHE AND YI [1993] consider the incentives of a single defendant to settle sequential suits when the judgments in early cases will bind on future cases. Other papers that explore information externalities in sequential litigation include Daughety And Reinganum [1999, 2002] and HuA AND SPIER [2005]. ${ }^{5}$

Several other papers in the law and economics literature have explored the incentives to plaintiffs to consolidate their claims into class actions for the purpose of litigation and/or settlement. CHE [1996] assumes that there are cost economies of consolidation, and that the plaintiffs who join a class will forgo fine-tuned awards and receive instead the average damage of the group. Che aruged that plaintiffs with weak cases are more

\footnotetext{
${ }^{3}$ See also Hay and Spier [1998] and Daughety and Reinganum [2005].

${ }^{4}$ Subsequent work includes Spier [1994], Klerman [1996], and Chang and Sigman [2000].

${ }^{5}$ Chог [2003] and BeвсhuK and Guzman [1996] study conflicts between plaintiffs and their attorneys; MeURer [1992] and Sykes [1994] explore externalities between defendants and liability insurers; SPIER AND Sykes [1998] consider conflicts between debt and equity; BAR-Gill and Ben-ShahaR [2007] explore externalites between criminal defendants; SpIER [2003a, 2003b] and DAUGHETY AND REINGANUm [2004] consider externalities created by most-favored-nations clauses.
} 
likely to join a class, since they would prefer to receive the average damage award, while plaintiffs with strong cases would opt out. The adverse selection problem is mitigated, however, when plaintiffs are privately informed. Weak plaintiffs have an incentive to remain independent, too, in an attempt to "signal" that they have strong cases and, in equilibrium, fewer weak plaintiffs join the class. CHE [2002] argues that classes may form to increase the members' bargaining power via information aggregation. The defendant is more generous when bargaining with the class as a whole than when bargaining with individuals.

The paper is organized as follows. Section 2 presents the basic model and characterizes an important benchmark. Section 3 characterizes the divide and conquer equilibrium when the defendant makes simultaneous offers to the plaintiffs, and discusses implications for class formation and incentives for care. Section 4 extends the basic model to sequential settlement offers, plaintiff bargaining power, and asymmetric information. Section 5 concludes.

\section{$2 \quad$ Model}

$N$ identical plaintiffs are suing a common defendant. The plaintiffs' aggregate damages are $D$. At trial, an individual plaintiff will receive an award equal to his share of the total damages,

$$
x(N)=\frac{D}{N} .
$$

This is the plaintiff's award regardless of how many other plaintiffs have settled their claims out of court. ${ }^{6}$ In contrast, a plaintiff's litigation cost will depend critically on how many other plaintiffs have settled (or dropped) their claims. Specifically, the aggregate litigation costs for the plaintiff and the defendant, $C_{p}$ and $C_{d}$, are assumed to be fixed. If $n \leq N$ plaintiffs go to trial, the litigating plaintiffs will split the fixed costs evenly, each plaintiff bearing

$$
c_{p}(n)=\frac{C_{p}}{n} .
$$

The per-capita net recovery for a plaintiff when litigating with a group of size $n$ is therefore given by

$$
x(N)-c_{p}(n)=\frac{D}{N}-\frac{C_{p}}{n} .
$$

Note that a plaintiff's net recovery at trial is decreasing in $N$, the total number of plaintiffs, but increasing in $n$, the number of plaintiffs who actually go to trial. We will

\footnotetext{
${ }^{6}$ In practice, the plaintiffs' aggregate recovery (and the defendant's corresponding liability) would often increase with the number of plaintiffs. See the accompanying discussion of REINGANum [forthcoming]. We adopt this normalization in order to isolate how the settlement externalities depend on the number of plaintiffs without changing the magnitude of the stakes.
} 
maintain the assumption throughout the paper that $D-C_{p}>0$. This implies that if all $N$ plaintiffs went to trial then each individual plaintiff would receive a positive net return, $x(N)-c_{p}(N)>0$.

A plaintiff's net return from going to trial alone will be positive if $N$ is small but negative if $N$ is large. It is easy to see why this is true. Suppose that $N=1$. This one plaintiff would surely derive positive value from litigating alone: $x(1)-c_{p}(1)=$ $D-C_{p}>0$. When $N=2$, however, the plaintiff's return from litigating alone is $x(2)-c_{p}(1)=D / 2-C_{p}$. He only receives half of the damages but bears the entire fixed cost. When $N=3$, a plaintiff's return from litigating alone falls even further, $x(3)-c_{p}(1)=D / 3-C_{p}$. The plaintiff's return from trial alone is clearly negative when $N$ is sufficiently large, for $D / N-C_{p} \rightarrow-C_{p}<0$ as $N \rightarrow \infty$. Let $N^{*}$ be defined as

$$
N^{*}:=\sup \left\{N \mid x(N)-c_{p}(1) \geq 0\right\} .
$$

In other words, $N^{*}$ is the largest integer where even a single plaintiff can achieve a positive net return at trial.

Next, we define $m(N)$ to be the smallest group size where plaintiffs in this group would enjoy a positive return if all $m(N)$ members of the group went to trial. That is,

$$
m(N):=\inf \left\{n \mid x(N)-c_{p}(n) \geq 0\right\}
$$

or, equivalently

$$
m(N):=\inf \left\{n \mid \frac{n}{N} \geq \frac{C_{p}}{D}\right\} .
$$

For a strategic purpose, $m(N)$ represents the minimal group size who can pose a credible threat to the defendant. Notice that $m(N)$ is weakly increasing in $N$. When $N \leq N^{*}$, $m(N)=1$, so even a single plaintiff has a positive expected value claim. If $N>N^{*}$, then $m(N)>1$. When $N$ increases in this range, a weakly larger group size $m(N)$ is required to make litigation jointly profitable for the plaintiffs. If we take the limit as $N$ approaches infinity we find that $m(N) / N$ converges to exactly $C_{p} / D$.

The timing of the game is as follows. In the first stage, the defendant makes offers to each of the $N$ plaintiffs, $\mathcal{S}=\left\{S_{1}, \ldots, S_{N}\right\}$. These offers are publicly observed. Without loss of generality, we will also assume that these offer are nondecreasing in $i$. In the second stage, the plaintiffs decide simultaneously and non-cooperatively whether to accept or reject their respective offers. Plaintiffs who accept offers immediately receive payment and exit the game. In the third stage, any remaining plaintiffs must decide simultaneously and non-cooperatively whether to drop their cases or proceed to trial. The trials take place in stage four. Our equilibrium concept throughout the paper is subgame perfect Nash equilibrium in coalition-proof strategies. More specifically, our equilibrium requires the strategies to form a Pareto-undominated Nash equilibrium for each subset of plaintiffs - namely for there to be no other strategies that provide strictly higher payoffs for any group of plaintiffs - in every subgame. This refinement, due to BERNHEIM, 
Peleg, And Whinston [1987], is employed here to ensure that the exploitation of the externalities does not simply stem from equilibrium selection or simple coordination failure on the part of the plaintiffs. While the plaintiffs are allowed to make coalition-proof acceptance decisions, we do not allow for explicit negotiation among plaintiffs with side payments. We shall later draw an implication of such negotiation abilities.

Before proceeding, it is useful to consider a benchmark in which the externalities facing the plaintiffs are fully internalized. This can be done for instance if the plaintiffs are represented by a benevolent agent who makes acceptance decisions for the plaintiffs in the joint best interest. The following observation is immediate.

Proposition 1. (Benchmark) If the plaintiffs make a jointly optimal decision, then the defendant's total payment or, equivalently, the plaintiffs' aggregate recovery, is $L^{*}(N)=$ $\sum_{i=1}^{N} S_{i}=D-C_{p}$.

\section{Analysis}

\subsection{Equilibrium Characterization}

This section characterizes the unique coalition-proof equilibrium of the game. In particular, we show that the defendant adopts a divide and conquer strategy that discriminates among the different plaintiffs. Some plaintiffs receive very generous settlement offers while other plaintiffs receive much less. Indeed, when the number of plaintiffs $N$ is large then a sizable fraction of the plaintiffs will receive nothing at all.

For the purpose of illustration, suppose that $N=2$ and that $x(2)-c_{p}(1)=D / 2-$ $C_{p}>0$. Each plaintiff has a credible unilateral threat to take the defendant to trial in this case. If the plaintiffs make jointly optimal decisions as in the previous benchmark, the defendant could do no better than offer $S_{1}=S_{2}=D / 2-C_{p} / 2$ to each plaintiff (plus a penny perhaps). The plaintiffs are weakly better off accepting these offers than going to trial, and the defendant pays a total of $S_{1}+S_{2}=D-C_{p}$ in settlement.

The defendant does strictly better when the plaintiffs make decentralized decisions, however. To see why, suppose that the defendant offers $S_{2}=D / 2-C_{p} / 2$ to the second plaintiff but makes a much less generous offer to the first plaintiff, $S_{1}=D / 2-C_{p}$. It is a dominant strategy for the second plaintiff to accept his relatively generous offer. Knowing this, the first plaintiff would accept the less generous offer. The defendant pays strictly less to the plaintiffs through this divide and conquer strategy: $S_{1}+S_{2}=$ $D-3 C_{p} / 2$. The defendant is, essentially, taking advantage of the plaintiffs' inability to internalize the settlement externalities.

The next proposition states the general result.

Proposition 2. There is a unique coalition-proof equilibrium of the game. The defendant offers $\mathcal{S}=\left\{S_{1}, \ldots, S_{N}\right\}$ where $S_{i}=\max \left\{0, x(N)-c_{p}(i)\right\}$, and these offers are all accepted by the plaintiffs. 
Proof: We can show that if the defendant offers $S_{i}$ to plaintiff $i=1, \ldots, N$, then it is a coalition-proof equilibrium for the plaintiffs to all accept the offers. To see this, take an arbitrary coalition $I_{k} \subset\{1, \ldots, N\}$ with $\left|I_{k}\right|=k \geq 1$. If all members of coalition $I_{k}$ rejected their offers, then each member of the coalition would receive $\max \{0, x(N)-$ $\left.c_{p}(k)\right\}$. Since $S_{i}$ is nondecreasing in $i$ by construction, we must have

$$
\max _{i \in I_{k}} S_{i} \geq S_{k}=\max \left\{0, x(N)-c_{p}(k)\right\}
$$

This implies that some member of coalition $I_{k}$ must receive a settlement offer of at least $\max \left\{0, x(N)-c_{p}(k)\right\}$. This is the amount that member would get if the coalition rejected their settlement offers and went to trial. This member is clearly weakly better off accepting the settlement offer. Therefore it is a coalition proof equilibrium for all plaintiffs to accept their respective offers.

Next, we show that $\mathcal{S}=\left\{S_{1}, \ldots, S_{N}\right\}$, where $S_{i}=\max \left\{0, x(N)-c_{p}(i)\right\}$ is the best sequence of offers that the defendant can make, given the coalition-proof refinement. Observe first that with $\mathcal{S}$, the defendant is paying strictly less to any coalition of plaintiffs than she would pay in total if she were to take that coalition to trial. This follows from the fact that $S_{i}<x(N)$ for all $i$ while at trial the defendant would pay on average more than $x(N)$ to for each plaintiff. Hence, it suffices to show that $\mathcal{S}$ is the lowest set of offers that she can make that will be accepted in any coalition-proof Nash equilibrium. To prove this, consider any set of offers $\tilde{\mathcal{S}}:=\left\{\tilde{S}_{1}, \ldots, \tilde{S}_{N}\right\}$ listed in the ascending order. Suppose $\tilde{S}_{k}<S_{k}=\max \left\{0, x(N)-c_{p}(k)\right\}$. Since the offers are in ascending order, we have

$$
\tilde{S}_{i}<S_{k}=\max \left\{0, x(N)-c_{p}(k)\right\} \text { for each } i=1, \ldots, k,
$$

Hence, in a coalition-proof Nash equilibrium, a coalition of plaintiffs $i=1, \ldots k$ will not accept the offers $\tilde{\mathcal{S}}$. This proves that for $\tilde{\mathcal{S}}$ to be accepted by the plaintiffs in a coalitionproof Nash equilibrium, we must have $\tilde{S}_{k} \geq S_{k}$ for each $k=1, \ldots, N$, which proves that $\mathcal{S}$ is the optimal offer for the defendant.

\subsection{Equilibrium Payoffs}

We now characterize the plaintiffs' payoffs and the defendant's loss in equilibrium, which will yield a useful implication later for ex ante deterrence. It follows from the equilibrium characterization that the defendant's total payments or, equivalently, the plaintiffs' aggregate recovery, is given by

$$
L(N)=\sum_{i=1}^{N} \max \left\{0, x(N)-c_{p}(i)\right\} .
$$

It is of particular interest to see how this function varies with the total number of plaintiffs. Since the upper bound for the loss, $L^{*}(N)=D-C_{p}$, is independent of $N$ 
(because of our normalization), this function $L(\cdot)$ will reveal whether the problem of externalities worsen or improve as a function of $N$.

Recall that $N^{*}$ is defined to be the largest number of plaintiffs where even a single plaintiff has a positive expected value claim. When $N \leq N^{*}$ then the first settlement offer in the set $\mathcal{S}$ is positive, or $S_{1}=x(N)-c_{p}(1)>0$. It follows that all of the settlement offers are strictly positive: $S_{i}=D / N-C_{p} / i, i=1, \ldots N$. The defendant's total settlement payments in this case may be written:

$$
L(N)=D-\sum_{i=1}^{N} \frac{C_{p}}{i}
$$

The sum $\sum_{i=1}^{N}(1 / i)$ is a called a "harmonic number" or $H_{N} . H_{N}$ is an increasing function and diverges slowly as $N$ approaches infinity. Hence, the function $L(N)$ is decreasing in the number of plaintiffs, $N$.

Now suppose instead that $N>N^{*}$. In this case, the equilibrium sequence of offers is characterized by $S_{i}=0$ for $i=0, \ldots, m(N)-1$ and $S_{i}=x(N)-c_{p}(N)=D / N-C_{p} / i$ for $i=m(N), \ldots N$. The defendant's total settlement payments as a function of $N$ are:

$$
L(N)=[N-m(N)+1] \frac{D}{N}-\sum_{i=m(N)}^{N} \frac{C_{p}}{i}
$$

$L(N)$ is decreasing in this range as well.

Proposition 3. The defendant's total payment, $L(N)$, is a decreasing function of $N$. Furthermore, $L(1)=D-C_{p}$ and, in the limit as $N$ approaches infinity, $L(N)$ converges to $D-C_{p}+C_{p} \ln \left(C_{p} / D\right)>0$.

Proof: We will first show that $L(N)$, is a decreasing function of $N$. The case of $N \leq N^{*}$ has already been proven. We will therefore focus on the second case where $N>N^{*}$. In this case, we can rewrite

$$
L(N)=D-[m(N)-1] \frac{D}{N}-C_{p} \sum_{i=m(N)}^{N} \frac{1}{i},
$$

where

$$
m(N)=\left\lceil\frac{N C_{p}}{D}\right\rceil
$$

(where $\lceil\cdot\rceil$ means the smallest integer no less than $(\cdot)$.) We are interested in signing $L(N+1)-L(N)$. To this end, observe first

$$
m(N+1)=\left\lceil\frac{N C_{p}}{D}+\frac{C_{p}}{D}\right\rceil \leq m(N)+1,
$$


since $C_{p}<D$. In other words, either $m(N+1)=m(N)$ or $m(N+1)=m(N)+1$. We consider each of the two cases in turn. Suppose first $m(N+1)=m(N)$. Then,

$$
\begin{aligned}
L(N+1)-L(N) & =[m(N)-1]\left(\frac{D}{N}\right)-[m(N)-1]\left(\frac{D}{N+1}\right)-\frac{C_{p}}{N+1} \\
& =\left[\frac{m(N)-1}{N+1}\right]\left[\frac{D}{N}-\frac{C_{p}}{m(N)-1}\right] \\
& \leq 0,
\end{aligned}
$$

where the inequality follows from the definition of $m(N)$.

Suppose next $m(N+1)=m(N)+1$. Then,

$$
\begin{aligned}
L(N+1)-L(N) & =[m(N)-1]\left(\frac{D}{N}\right)-m(N)\left(\frac{D}{N+1}\right)-\frac{C_{p}}{N+1}+\frac{C_{p}}{m(N)} \\
& =\left[\frac{m(N)}{N+1}\right]\left[\frac{D}{N}-\frac{C_{p}}{m(N)}\right]-\frac{D}{N}+\frac{C_{p}}{m(N)} \\
& =\left[\frac{m(N)-(N+1)}{N+1}\right]\left[\frac{D}{N}-\frac{C_{p}}{m(N)}\right] \\
& \leq 0
\end{aligned}
$$

where the inequality holds since $D / N-C_{p} / m(N) \geq 0$ and since $m(N)<N+1$.

Next, we will establish the limit as $N$ approaches infinity. Rewrite the defendant's total payments as:

$$
L(N)=D-D\left[\frac{m(N)+1}{N}\right]-C_{p} \sum_{i=1}^{N} \frac{1}{i}+C_{p} \sum_{i=1}^{m(N)-1} \frac{1}{i} .
$$

or

$$
L(N)=D-D\left[\frac{m(N)+1}{N}\right]-C_{p} H_{N}+C_{p} H_{m(N)-1}
$$

We will now take the limit as $N$ approaches infinity. The harmonic number $H_{N}$ has the property that $\lim \left[H_{N}-\ln (N)\right]=\gamma$ where $\gamma$ is the Euler constant $0.57721 \ldots$. We therefore have

$$
\lim L(N)=D-D \lim \left[\frac{m(N)+1}{N}\right]+C_{p} \lim [\ln [m(N)-1]-\ln (N)]
$$

or

$$
\lim L(N)=D-D \lim \left[\frac{m(N)+1}{N}\right]+C_{p} \lim \ln \left[\frac{m(N)-1}{N}\right] .
$$

In the limit we have

$$
\frac{m(N)-1}{N}=\frac{C_{p}}{D}
$$


So we have

$$
\lim L(N)=D-C_{p}+C_{p} \ln \frac{C_{p}}{D} .
$$

It is straightforward to show that this is positive for all $C_{p}<D$. Let $x=C_{p} / D$. By our earlier assumptions, we know that $x \in(0,1)$. To show that $\lim L(N)$ is positive, it is sufficient to show that $f(x)=1-x+x \ln x>0$ for all $x \in(0,1)$. We know that this is true because $f(1)=0$ and $f^{\prime}(x)=\ln (x)<0$ for all $x \in(0,1)$.

\subsection{Implications and Discussion}

The previous section showed that plaintiffs are jointly exploited by the defendant through settlement. The negative externality associated with individual settlement decisions leads the plaintiffs to settle their claims for too little overall. In aggregate, the plaintiffs receive less than $D-C_{p}$, what they would receive if they all went to trial. Moreover, their joint payoff is falling in the number of plaintiffs. These results have important implications for both the incentives of the defendant to take precautions to avoid accidents to begin with, and the incentives of plaintiffs to organize themselves into classes.

Importantly, the presence of multiple plaintiffs reduces the incentives of the defendant to take care. This follows immediately from the fact that $L(N)<D-C_{p}$ whenever $N>1$. This is an important result. Although the defendant is exploiting plaintiffs through settlement ex post, there are no ex post welfare implications of this exploitation. The exploitation leads to a simple redistribution of value away from the plaintiffs and towards the defendant. When ex ante behavior is taken into account, however, then we find that the bargaining outcome is relevant for social welfare. If the defendant would take optimal or even suboptimal precautions when he expects to pay $D-C_{p}$ to the victims of an accident, social welfare will surely fall when $L(N)<D-C_{p}$. Moreover, this welfare loss is larger when the number of plaintiffs, $N$, rises.

The plaintiffs clearly have a joint incentive to overcome this problem of externalities. There are several ways for the plaintiffs to accomplish this objective.

First, the plaintiffs might agree to make a single acceptance decision for all plaintiffs, decided by a unanimous rule (after the defendant's offers). ${ }^{7}$ Given such a commitment, the plaintiff who received the smallest offer will be pivotal in making acceptance decision. Under the unanimity rule, this plaintiff can send the entire class to trial by vetoing the proposal, and doing so will give him a payoff of $\left(D-C_{p}\right) / N$. Plaintiffs will clearly reject offers for less than this amount, and so the defendant can do no better than offer $\left(D-C_{p}\right) / N$ to each and every to every plaintiff.

\footnotetext{
${ }^{7}$ We consider ex post contracting by the plaintiffs, made only after the defendant makes offers to the plaintiffs. If the plaintiffs can make ex ante commitment, they may be able to do better. They might be able to commit themselves to only accept offers that are, in aggregate, higher than $D+C_{d}$. Such a strategy would be susceptible to renegotiation, however.
} 
Second, the same outcome could be attained ex ante if the plaintiffs can commit not to entertain discriminatory offers by the defendant. If such a commitment is credible, then the defendant must make the same offer to every plaintiff. Whenever the uniform offer is strictly less than $\left(D-C_{p}\right) / N$, it is a coalition-proof Nash response by the plaintiffs to reject the offer (individually), and realize the aggregate payoff of $D-C_{p}$ jointly from trial. ${ }^{8}$ Hence, the defendant will offer $\left(D-C_{p}\right) / N$ to every plaintiff, just as in the benchmark. Plaintiffs may achieve such a commitment with the help of a policy or court regulation prohibiting discriminatory offers. Indeed, in class action suits, courts often intervene settlement processes, in large part to protect the interest of the minority plaintiffs. Such a protection of minority interests may very well serve to limit the ability by the defendant to exploit the plaintiffs via its divide and conquer strategy. To the extent that such a regulation restores socially desirable deterrence (or, as in Section 4, a reduction in the incidence of costly trials), the current paper provides a rationale for the courts' regulation of settlement procedures.

Finally, the plaintiffs may overcome the externalities problem by exchanging side payments after receiving the offers from the defendant. As is well-known from the Coase theorem, unexplored externalities on the part of the plaintiffs can be realized through negotiation among them. For instance, the plaintiffs who expect to be harmed by settling plaintiffs can bribe the latter not to settle, thus realizing the scale economies of litigation, whenever it is jointly beneficial. Again the ability to exchange side transfers can be achieved within the organizational framework such as class actions or other mechanisms that permit or even encourage such a negotiation.

Proposition 4. The plaintiffs can induce an aggregate offer from the defendant of D$C_{p}$, (i) if they can commit to make a single acceptance decision via a unanimous rule, or (ii) if they can commit not to accept discriminatory offers, or (iii) if they can exchange side payments.

\section{Extensions and Robustness of Results}

We show here that the exploitation of the plaintiffs' externalities is robust to a number of extensions of our model.

\subsection{Sequential Offers}

Suppose that the defendant approaches plaintiffs in predetermined order, $i=1, \ldots N$, and makes a sequence of take-it-or-leave-it offers, $S_{1}, \ldots S_{N}$. Plaintiff $i$ must either accept or reject $S_{i}$ before the defendant moves on to plaintiff $i+1$, and the same process is repeated

\footnotetext{
${ }^{8}$ Although it may also be a Nash equilibrium for the plaintiffs to all accept lesser offers, acceptance is Pareto dominated for the plaintiffs.
} 
with the full knowledge on both sides about the prior history of bargaining. After the last plaintiff, plaintiff $N$, has made his acceptance decision, all remaining plaintiffs decide simultaneously and non-cooperatively, but again in a coalition-proof fashion, whether to proceed to trial. We will restrict attention to the case where $N>N^{*}$, so $m(N)>1$ and no plaintiff could profit from going to trial alone.

We show in this case that the defendant can exploit the plaintiffs' negative externalities to a point that no plaintiff can receives any positive payoff. This is indeed a unique subgame perfect equilibrium outcome that satisfies the coalition-proof refinement. Suppose that the defendant reaches the last plaintiff, and there have been $n<N$ rejections so far. If the last plaintiff rejects his or her settlement offer, then the coalition of plaintiff $N$ and the other $n$ plaintiffs will go to trial if and only if $n+1 \geq m$. Therefore plaintiff $N$ 's outside option is $\max \left\{0, x(N)-c_{p}(n+1)\right\}$. If the defendant were to offer

$$
\hat{S}_{n}:=\max \left\{0, x(N)-c_{p}(n+1)\right\}
$$

then the plaintiff would be (just) willing to accept. The defendant is certainly better off settling with plaintiff $N$ on these terms, since he would otherwise pay $x(N)$ to the plaintiff at trial. (Since $c_{d}$ is fixed, there are no incremental costs of the additional plaintiff.)

Working backwards, suppose the defendant reaches the $k$ th plaintiff in the sequence. Arguing inductively, assume that the defendant will settle with all subsequent plaintiffs. Then, the same argument as above establishes that, if there have been $j$ rejections up to that point, the defendant will offer in that subgame $\hat{S}_{j}:=\max \left\{0, x(N)-c_{p}(j+1)\right\}$, which is in turn accepted by the plaintiff. We therefore conclude that in a unique SPE outcome has, in any subgame following $j$ rejections, the defendant offer $\hat{S}_{j}$ and the plaintiff accepts it.

Applying this outcome to the first round bargaining, the defendant offers $\hat{S}_{0}=$ $\max \left\{0, x(N)-c_{p}(1)\right\}$, and this is accepted by the first plaintiff. By our earlier assumption, $x(N)-c_{p}(1)<0$ so we have $S_{0}=0$. The same behavior is repeated throughout. That is, all plaintiffs receive zero payoffs. We have arrived at the following conclusion:

Proposition 5. Suppose $m(N)>1$. If the defendant approaches the plaintiffs sequentially, making take-it-or-leave-it settlement demands to each, then plaintiffs earn payoffs of zero in equilibrium.

The externalities problem is clearly worse when $m(N)>1$ and the defendant makes sequential settlement offers. Interestingly, unlike the case of simultaneous offers, prohibiting the defendant from making discriminatory offers does not solve the problem. To see this, suppose the defendant faces two plaintiffs in sequence, and $m(2)=2$, and the defendant is required to offer to the second plaintiff the same amount as the one accepted by the first plaintiff. Suppose the defendant begins with a zero settlement to the first plaintiff. If this offer is accepted, then the second plaintiff has no case and will 
be willing to settle at zero, which is exactly when the defendant will offer, in compliance with the regulation. If the first plaintiff refuses the zero offer, however, then the regulation has no bite, and the defendant is free to raise her offer to $\left(D-C_{p}\right) / 2$ to the second plaintiff. This ability to raise the offer to a later plaintiff is precisely what enables the defendant to exploit the plaintiffs' externalities to such an extreme degree. A typical non-discrimination clause (which has a binding effect only when earlier offers are accepted) does not diminish that ability.

\subsection{Plaintiff Bargaining Power}

Suppose instead that the plaintiffs make simultaneous take-it-or-leave-it offers to the defendant. We continue to restrict attention to the case where $N>N^{*}$, so $m(N)>1$ and no plaintiff could profit from going to trial alone. After receiving the set of offers, the defendant decides which (if any) of the offers to accept and which to reject. The plaintiffs are then informed of the defendant's decision and the decide, simultaneously and non-cooperatively, but in a coalition-proof fashion, whether to drop their claims or proceed to trial.

Since a single plaintiff will not pursue litigation, it is easy to see that there is an equilibrium where all the plaintiffs receive a zero payoff. Suppose that each plaintiff demands settlement of 0 , and the defendant accepts these offers. Clearly, no profitable deviation exists. If a plaintiff unilaterally deviates and demands a strictly positive offer, the defendant will simply reject that offer (and accept all other offers of zero), and the deviating plaintiff, being the lone plaintiff with a rejected offer, is unable to mount a viable litigation.

More surprisingly, we show that this equilibrium is unique in pure strategies, so it is coalition proof (in pure strategies). This proof involves several steps.

First, we will show that there cannot be any trials on the equilibrium path. Suppose to the contrary that a set $I$ or plaintiffs with size $|I|=k>1$ proceed to trial. It follows that the settlement demands $S_{i}$ of each plaintiff in this coalition, $i \in I$, must have been rejected by the defendant before trial. The defendant would have been weakly better off settling with a single plaintiff in this group, $i \in I$, for an amount $S_{i}$ so long as $S_{i} \leq \bar{S}_{i}$ where

$$
\bar{S}_{i}+\sum_{j \in N \backslash I} S_{j}+(k-1) x(N)=\sum_{j \in N \backslash I} S_{j}+k x(N) .
$$

The left hand side of this expression represents the defendant's payments if he settles with plaintiff $i$ (for $\bar{S}_{i}$ ) and the coalition $N \backslash I$, but litigates against the remaining $k-1$ plaintiffs. The right hand side represents the defendant's payments if he settles with the coalition $N \backslash I$ and litigates against the remaining $k$ plaintiffs. Rearranging terms we have

$$
\bar{S}_{i}=x(N)
$$


The very least a single plaintiff $i \in I$ would be willing to accept for settlement is

$$
\underline{S}_{i}=x(N)-c_{p}(k)<x(N) \text {. }
$$

The fact that $\underline{S}_{i}<\bar{S}_{i}$ implies that a profitable deviation exists where a plaintiff can unilaterally change his settlement demand to $S \in\left(\underline{S}_{i}, \bar{S}_{i}\right)$ and induce the defendant to accept. Since plaintiff $i$ is and the defendant are strictly better from such a deviation, the hypothesized behavior, and hence trial, can never occur on the equilibrium path.

Second, we will prove that there must be at least one plaintiff receives a zero payoff in equilibrium. Suppose to the contrary that all plaintiffs receive strictly positive payoffs in equilibrium. Since no trials occur in equilibrium by our previous argument, it must be the case that the defendant accepts strictly positive settlement demands from all of the plaintiffs. Clearly, this cannot be an equilibrium. Rather than accepting all of the settlement offers, the defendant could have done strictly better by rejecting at least $m-1$ such offers. (Once their offers are rejected, the $m-1$ plaintiffs will rationally drop their claims.)

Finally, we show that no plaintiff can earn a strictly positive payoff in equilibrium. Suppose to the contrary that a plaintiff $i$ earns strictly positive payoff. This is possible, given no trial, only if that plaintiff's settlement demand $S_{i}>0$ is accepted by the defendant in equilibrium. By the previous claim, there also exists a plaintiff (call him plaintiff $j$ ) who receives a zero payoff. Suppose that plaintiff $j$ unilaterally deviated and made a settlement demand just slightly below the demand of plaintiff $i, S_{j}=S_{i}-\epsilon$. The defendant would receive a higher payoff by accepting $S_{j}$ and rejecting $S_{i}$. Hence, there will be no plaintiff with zero payoff, which contradicts our earlier claim that there must exist a plaintiff who receives a zero payoff.

We have arrived at the following conclusion:

Proposition 6. Suppose $m(N)>1$. In any pure-strategy equilibrium of the game where the plaintiffs make simultaneous take-it-or-leave-it settlement demands to the defendant, the plaintiffs earn payoffs of zero.

\subsection{Asymmetric Information}

We now extend our previous analysis to include asymmetric information. Doing so allows us to investigate the robustness of our results as well as the equilibrium bargaining behavior in the presence of asymmetric information; but more importantly, asymmetric information introduces positive probability of trial on the equilibrium path, so it gives us an opportunity to study how the bargaining externalities affect the settlement/trial rate. Rather than considering a general number of plaintiffs, we focus on the case where $N=2$. In this extension, the plaintiffs are privately informed about their (expected) damage levels. We will see that the equilibrium is similar in many ways to the one that would arise with complete information. First, the defendant adopts a divide and 
conquer strategy, offering more to one plaintiff than to the other. Second, the plaintiffs are worse off in this equilibrium than they would be if they consolidated their claims or could exchange side payments with each other. Last but not the least, it will be seen that the inability to internalize litigation externalities leads to reduced incidence of trial.

Suppose that two plaintiffs are facing a defendant. Each plaintiff has expected damages $x$ distributed (independently) over $\left\{x_{L}, x_{H}\right\}$ with probabilities $1-\lambda$ and $\lambda$, respectively, where $x_{H}>x_{L}>0$. Further, we assume that

$$
\frac{C_{p}}{2}<x_{L}<x_{H}<C_{p}
$$

That is, a lawsuit is profitable jointly but not so by oneself, regardless of the types. This model introduces an interaction between litigation externalities and endogenous settlement in a simple fashion.

The defendant makes a pair of offers $\left(S_{1}, S_{2}\right)$ simultaneously, followed by the plaintiffs deciding whether to accept and reject those offers. The plaintiffs' decisions are made in a Pareto efficient fashion; namely, the equilibrium decisions made on any pair $\left(S_{1}, S_{2}\right)$ must be such that there is no other decisions on their part that will strictly Pareto dominate the decisions. This ability to make a Pareto undominated decision does not mean that the two plaintiffs will behave like a single decision maker. The source of transaction cost or imperfect coordination here is two fold: First, the plaintiffs cannot use transfers to overcome the externalities problem, just as in the previous setting. Second, the plaintiffs do not observe each other's types, which could lead to a less than perfect coordination between two plaintiffs. To appreciate how the externalities affect the settlement decisions and outcomes, it is useful to begin with a benchmark in which the two plaintiffs are able to perfectly coordinate their behavior, with the ability to exchange transfers and to observe each other's type.

\subsubsection{Benchmark: Perfect Coordination}

Suppose the defendant has offered $\left(S_{1}, S_{2}\right)$. The plaintiffs decide whether to accept the offers in a way that maximize their joint payoffs, possibly making side payments to each other. It is then clear then that the plaintiffs will never accept only one offer. They will either accept both offers or neither offer. There are three possible strategies for the defendant:

First, the defendant may choose to induce the plaintiff coalition to accept if and only if they have both low damages. The necessary aggregate offer is $S_{L L}=2 x_{L}-C_{p}$. In this case, the defendant's expected loss is

$$
L_{L L}:=(1-\lambda)^{2}\left[2 x_{L}-C_{p}\right]+2 \lambda(1-\lambda)\left[x_{L}+x_{H}+C_{d}\right]+\lambda^{2}\left[2 x_{H}+C_{d}\right] .
$$

Second, the defendant may choose to induce the coalition to accept if and only if they have one low and one high damages, or they both have low damages. The necessary 
total offer is $S_{L H}=x_{L}+x_{H}-C_{p}$. In this case, the defendant's expected loss is

$$
L_{L H}:=\left(1-\lambda^{2}\right)\left[x_{L}+x_{H}-C_{p}\right]+\lambda^{2}\left[2 x_{H}+C_{d}\right] .
$$

Third, the defendant may choose to induce settlement with certainty by offering $S_{H H}=2 x_{H}-C_{p}$ in total. Obviously, the defendant's expected loss in this case is

$$
L_{H H}:=2 x_{H}-C_{p}
$$

There are two threshold values,

$$
\hat{\lambda}_{1}:=\frac{x_{H}-x_{L}}{x_{H}-x_{L}+2\left(C_{p}+c_{d}\right)}, \hat{\lambda}_{2}:=\sqrt{\frac{x_{H}-x_{L}}{x_{H}-x_{L}+C_{p}+C_{d}}}
$$

such that the first strategy is optimal if $\lambda<\hat{\lambda}_{1}$, the second is optimal if $\lambda \in\left[\hat{\lambda}_{1}, \hat{\lambda}_{2}\right]$ and the third is optimal if $\lambda \geq \hat{\lambda}_{2}$. The trial probability is then

$$
\tau^{*}(\lambda):= \begin{cases}1-(1-\lambda)^{2} & \text { if } \lambda \leq \hat{\lambda}_{1} \\ \lambda^{2} & \text { if } \lambda \in\left[\hat{\lambda}_{1}, \hat{\lambda}_{2}\right] \\ 0 & \text { if } \lambda \geq \hat{\lambda}_{2}\end{cases}
$$

\subsubsection{Equilibrium Analysis}

Suppose now the plaintiffs now make Pareto undominated acceptance decisions in response to any pair of offers $\left(S_{1}, S_{2}\right)$ that the defendant may make. The equilibrium may involve the defendant adopting one of the following divide and conquer strategies.

Strategy L: The defendant induces only one plaintiff to accept her offer only when he has low damages.

Suppose plaintiff 1 is induced to accept when $x=x_{L}$. Minimal offers that accomplish this outcome is $\left(S_{1}, S_{2}\right)=\left(x_{L}-C_{p} / 2,0\right)$. Since plaintiff 2 rejects his offer, any lower offer to plaintiff 1 will be rejected even when he has low damages. The defendant's expected loss is then

$$
\tilde{L}_{L}(\lambda):=(1-\lambda)\left(x_{L}-\frac{C_{p}}{2}\right)+\lambda\left[(1-\lambda)\left(x_{L}+x_{H}+C_{d}\right)+\lambda\left(2 x_{H}+C_{d}\right)\right] .
$$

StRATEGy LL: The defendant induces each plaintiff to accept her offer only when he has low damages.

Minimal offers that accomplish this outcome is $\left(S_{1}, S_{2}\right)=\left(x_{L}-C_{p} / 2, \lambda\left(x_{L}-C_{p} / 2\right)\right)$. Even though only a low type plaintiff is induced to accept, given the externalities, the lawsuit arises only when both plaintiffs have high types. A high damage plaintiff who rejects his offer is unable to litigate when the other plaintiff settles. In other words, 
the defendant accomplishes the same outcome as she would have in the benchmark by offering $S_{L H}$ in total settlement. Observe that a strictly smaller amount $S_{1}+S_{2}=$ $(1+\lambda)\left(x_{L}-C_{p} / 2\right)<S_{L H}$ is needed to accomplish the same outcome due to the plaintiffs' inability to coordinate their behavior. The defendant's expected loss is then

$$
\tilde{L}_{L L}(\lambda):=\left(1-\lambda^{2}\right)\left(x_{L}-\frac{C_{p}}{2}\right)+\lambda^{2}\left(2 x_{H}+C_{d}\right) .
$$

Notice that, with these offers, the defendant faces a lawsuit only when both plaintiffs have high damages.

Strategy H: The defendant induces only one plaintiff to accept her offer, regardless of his type.

Assume without loss that plaintiff 1 is induced to accept the offer. Minimal offers that accomplish this outcome is $\left(S_{1}, S_{2}\right)=\left(x_{H}-C_{p} / 2,0\right)$. By offering $x_{H}-C_{p} / 2$ in total, the defendant can avoid any trial. Recall that twice this amount, $S_{H H}=2 x_{H}-C_{p}$, was needed to achieve the same outcome if the plaintiffs were able to coordinate their decisions. The defendant's expected loss is then

$$
\tilde{L}_{H}:=x_{H}-\frac{C_{p}}{2} .
$$

Notice that the defendant faces no lawsuit from plaintiff 2, now that plaintiff 1 settles always. In fact, plaintiff 2 may as well accept the zero settlement. Strategy $H$ also employs divide and conquer tactics.

There is no other strategy that the defendant may use. For instance, the strategy of inducing settlement from one plaintiff always and from the other only when he has low type is the same as Strategy $H$.

In fact, strategy $\mathrm{L}$ is dominated by strategy LL, for

$\tilde{L}_{L}(\lambda)-\tilde{L}_{L L}(\lambda)=-(1-\lambda) \lambda\left(x_{L}-\frac{C_{p}}{2}\right)+\lambda(1-\lambda)\left(x_{L}+x_{H}+C_{d}\right)=\lambda(1-\lambda)\left(x_{H}+C_{d}+\frac{C_{p}}{2}\right)>0$.

Consequently, we can simply focus on the comparison between strategy LL and strategy H. It follows that there exists

$$
\tilde{\lambda}:=\sqrt{\frac{x_{H}-x_{L}}{2 x_{H}-x_{L}+\frac{C_{p}}{2}+C_{d}}} \in\left(0, \frac{1}{2}\right) .
$$

such that the defendant adopts Strategy $L L$ if $\lambda \leq \tilde{\lambda}$ and Strategy $H$ if $\lambda \geq \tilde{\lambda}$. Trial occurs with probability

$$
\tau(\lambda):= \begin{cases}\lambda^{2} & \text { if } \lambda \leq \tilde{\lambda} \\ 0 & \text { if } \lambda \geq \tilde{\lambda}\end{cases}
$$

It is instructive to compare the equilibrium outcome in terms of the probability trial as well as of the defendant's payment: 
Proposition 7. When the plaintiffs are privately informed about their damages, the defendant adopts a divide and conquer strategy. Trial occurs with a lower probability in equilibrium than in the full-coordination benchmark (more precisely, $\tau(\lambda) \leq \tau^{*}(\lambda)$, with strict inequality for a positive measure of $\lambda$ ). The defendant's payment is lower in equilibrium than in the benchmark.

Proof: We first observe that

$$
\begin{aligned}
\tilde{\lambda} & =\sqrt{\frac{x_{H}-x_{L}}{2 x_{H}-x_{L}+\frac{C_{p}}{2}+C_{d}}} \\
& =\sqrt{\frac{x_{H}-x_{L}}{x_{H}-x_{L}+\left(x_{H}-\frac{C_{p}}{2}\right)+C_{p}+C_{d}}} \\
& <\sqrt{\frac{x_{H}-x_{L}}{x_{H}-x_{L}+C_{p}+C_{d}}} \\
& =\hat{\lambda}_{2} .
\end{aligned}
$$

Hence, for $\lambda \in\left(\tilde{\lambda}, \hat{\lambda}_{2}\right), \tau(\lambda)=0<\tau^{*}(\lambda)=\lambda^{2}$. Now consider any $\lambda \leq \min \left\{\tilde{\lambda}, \hat{\lambda}_{1}\right\}$. In this case, $\tau(\lambda)=\lambda^{2}<1-(1-\lambda)^{2}=\tau^{*}(\lambda)$. In all other values of $\lambda, \tau(\lambda)=\tau^{*}(\lambda)$. This proves the first statement. The last statement follows from the fact that

$$
\min \left\{\tilde{L}_{L L}, \tilde{L}_{H}\right\}<\min \left\{L_{L L}, L_{L H}, L_{H H}\right\} .
$$

It is not difficult to see why trial is less likely to occur when there are litigation externalities. A plaintiff fails to internalize the cost he imposed on the other plaintiff when settling with the defendant. Consequently, either plaintiffs settle too easily or they fail to coordinate on their litigation, leaving a plaintiff stranded unable to litigate against the defendant after rejecting her offer. ${ }^{9}$ As before, the defendant is a clear beneficiary of this inability of the plaintiffs to internalize the externalities, which she exploits by the "divide and conquer" strategy, even in the presence of asymmetric information. The reduced payment by the defendant again implies her reduced incentive to take care. At the same time, the reduced likelihood of trial is socially desirable because of the reduced litigation expenditures. Hence, unlike the case of symmetric information, the exploitation of plaintiffs has a welfare benefit which must be weighed against the loss from weakened deterrence (if such a loss exists).

\footnotetext{
${ }^{9}$ Interestingly, the plaintiffs in our problem need not settle with probability $1-\tau(\lambda)$. For instance, when the defendant employs strategy $L L$, then a high type plaintiffs rejects the defendant's offer in equilibrium, but fails to proceed to litigate the defendant if the other plaintiff happens to be a low type.
} 


\section{Conclusion}

This paper looked at a simple bargaining model with a single defendant and $N$ plaintiffs when there are fixed costs of litigation that will be spread among the plaintiffs who go to trial. Externalities naturally arise in this setting because the decision of one plaintiff to settle with the defendant out of court dilutes the value of the remaining plaintiffs' claims. We showed that these externalities put the plaintiffs in a unusually vulnerable position when bargaining with the defendant.

We started with the case where the defendant makes simultaneous take-it-or-leave-it offers to the plaintiffs. The defendant adopted divide and conquer strategies in this case, offering more to some plaintiffs than to others. Importantly, the defendant easily exploited the plaintiffs through these strategies, coercing them into settling their claims for less than they were jointly worth at trial. Moreover, we showed that the plaintiffs were worse off when the number of plaintiffs is larger and when the defendant's settlement offers are sequential instead of simultaneous. Somewhat surprisingly, the plaintiffs are be worse off still when they had the power to make simultaneous take-it-or-leave-it offers to the defendant.

The analysis presented here has both positive and normative implications. On the positive side, the analysis implies that the plaintiffs have a motive to write contracts with each other and coordinate their strategies to improve their joint payoffs. This may be accomplished through simple transfer payments among the plaintiffs, through explicit voting rules, and through covenants not to accept discriminatory offers. On the normative side, the fact that the settlement externalities favor the defendant implies that the defendant's incentives to take precautions at an ex ante stage are weakened. This could, of course, be bad for society overall. Our analysis also highlights potential social benefits stemming from divide and conquer strategies. In the presence of asymmetric information, we showed that the settlement rate was higher and overall litigation spending correspondingly lower than would be the case if the plaintiffs were able coordinate their strategies. This social benefit would counterbalance, to a greater or lesser extent, the potential social losses due to reduced deterrence. 


\section{References}

[1] Bar-Gill, O. And Ben-Shahar, O. [2007], "The Prisoners (Plea Bargain) Dilemma," New York University School of Law, New York University Law and Economics Working Papers, Paper 97.

[2] Bebchuk, L. A. And Guzman, A. [1996], "How Would You Like To Pay For That? The Strategic Effects of Fee Arrangements on Settlement Terms," Harvard Negotiation Law Review, 1, 53-63.

[3] Bernheim, B. D., Peleg, B., And M. D. Whinston [1987], "Coalition-Proof Nash Equilibria 1. Concepts," Journal of Economic Theory, 42, 1-12.

[4] Caillaud, B. And B. Jullien [2003], "Chicken and Egg: Competition among Intermediation Service Providers", The RAND Journal of Economics, 24, 521-552.

[5] Chang, H.F. And Sigman, H. [2000], "Incentives to Settle Under Joint and Several Liability: An Empirical Analysis of Superfund Litigation," Journal of Legal Studies, 24, 205-236.

[6] Che, Y.-K. [1996], "Equilibrium Formation of Class Action Suits," Journal of Public Economics, 62, 339-361.

[7] Che, Y.-K. [2002], "The Economics of Collective Negotiations in Pretrial Bargaining," The International Economic Review, 43, 549-576.

[8] Che, Y.-K. And Yi, J.G. [1993], "The Role of Precedents in Repeated Litigation," Journal of Law, Economics, and Organization, 9, 399-424.

[9] Chor, A. [2003], "Allocating Settlement Authority Under a Contingent-Fee Arrangement," The Journal of Legal Studies, 32, 585-610.

[10] Cooter, R. D. And Rubinfeld, D. L. [1989], "Economic Analysis of Legal Disputes and Their Resolution," Journal of Economic Literature, 27, 1067-1097.

[11] Daughety, A.F. (2000) "Settlement," In Encyclopedia of Law and Economics, B. Bouckaert and G. De Geest, eds., Edward Elgar Publishing Co. 5, 95-158.

[12] Daughety, A. F. And Reinganum, J. F. [1999] "Hush Money', RAND Journal of Economics, 30, 661-678.

[13] Daughety, A. F. And Reinganum, J. F. [2002] "Information Externalities in Settlement Bargaining: Confidentiality and Correlated Culpability," RAND Journal of Economics, 33, 587-604. 
[14] Daughety, A. F. And Reinganum, J. F. [2004], "Exploiting Future Settlements: A Signaling Model of Most-Favored-Nation Clauses in Settlement Bargaining," RAND Journal of Economics, 35, 467-485.

[15] Daughety, A. F. And Reinganum, J. F. [2005], "Economic Theories of Settlement Bargaining," Annual Review of Law and Social Science, 1, 35-59.

[16] Grossman, S. and O. Hart [1988], "One Share - One Vote and the Market for Corporate Control," Journal of Financial Economics, 20, 175-202.

[17] Hay, B. And Spier, K. E. [1998], "Settlement of Litigation," In Peter Newman, ed., The New Palgrave Dictionary of Economics and the Law, Macmillan Reference Limited, 3, 442-451.

[18] Hua, X. And Spier, K. E. [2005], "Information and Externalities in Sequential Litigation," Journal of Institutional and Theoretical Economics, 161, 215-32.

[19] Innes, R. And R. J. Sexton [1994], "Strategic Buyers and Exclusionary Contracts," American Economic Review, 84, 566-584.

[20] Klerman, D. [1996], "Settling Multidefendant Lawsuits: The Advantage of Conditional Setoff Rules," Journal of Legal Studies, 25, 445-461.

[21] Kornhauser, L. A. and Revesz, R. L. [1994a], "Multidefendant Settlements: The Impact of Joint and Several Liability," Journal of Legal Studies, 23, 41-76.

[22] Kornhauser, L. A. and Revesz, R. L. [1994b], "Multidefendant Settlements under Joint and Several Liability: The Problem of Insolvency," Journal of Legal Studies, 23, 517-542.

[23] Meurer, M. [1992], "The Gains From Faith in an Unfaithful Agent: Settlement Conflict Between Defendants and Liability Insurers," Journal of Law, Economics and Organization, 8, 502-522.

[24] Miller, G. P. [1998], "Class Actions," In Peter Newman, ed., The New Palgrave Dictionary of Economics and the Law, Macmillan Reference Limited, 1, 257-262.

[25] Polinsky, A. M. And Rubinfeld, D. L. [1988], "The Deterrent Effects of Settlements and Trials," International Review of Law and Economics, 8, 109-116.

[26] Rasmusen, E. B., Rasmeyer, J. M. and J. S. Wiley Jr., [1991], "Naked Exclusion," American Economic Review, 81, 1137-1144.

[27] Reinganum, J. F. [forthcoming], "Comments on 'Exploiting Plaintiffs Through Settlement: Divide and Conquer'," Journal of Institutional and Theoretical Economics. 
[28] Segal, I. [1999], "Contracting with Externalities," Quarterly Journal of Economics, 114, 337-388.

[29] Segal, I. [2003], "Coordination and Discrimination in Contracting with Externalities: Divide and Conquer," Journal of Economic Theory, 113, 147-181.

[30] Segal, I. And M. Whinston, [2000], "Naked Exclusion: Comment," American Economic Review, 90, 296-309.

[31] Segal, I. and M. Whinston, [2003], "Robust Predictions for Bilateral Contracting with Externalities," Econometrica, 71, 757-791.

[32] Shavell, S. [1997], "The Fundamental Divergence Between the Private and the Social Motive to Use the Legal System," Journal of Legal Studies, 26, 575-613.

[33] Spier, K. E. [1994], "A Note on Joint and Several Liability: Insolvency, Settlement, and Incentives," Journal of Legal Studies, 23, 559-68.

[34] SpIER, K. E. [2002], "Settlement with Multiple Plaintiffs: The Role of Insolvency," Journal of Law, Economics, and Organization, 18, 295-323.

[35] SpIER, K. E. [2003a], "The Use of Most-Favored-Nation Clauses in Settlement of Litigation," The RAND Journal of Economics, 34, 78-95.

[36] Spier, K. E. [2003b], "Tied To the Mast: Most-Favored-Nation Clauses in Settlement Contracts," Journal of Legal Studies, 32, 91-120.

[37] Spier, K. E. [2005], "Economics of Litigation," in L. E. Blume and S. N. Durlauf, The New Palgrave Dictionary of Economics, 2nd ed., Palgrave McMillan.

[38] Spier, K. E. [2007], "Litigation," in The Handbook of LaW and Economics, A. Mitchell Polinsky and Steven Shavell, eds., North Holland, 265-345.

[39] Spier, K. E. and Sykes, A. O. [1998], "Capital Structure, Priority Rules, and the Settlement of Civil Claims," The International Review of Law and Economics, 18, 187-200.

[40] Stremitzer, A. [forthcoming], "Comments on 'Exploiting Plaintiffs Through Settlement: Divide and Conquer'," Journal of Institutional and Theoretical Economics.

[41] Sykes, A. O. [1994], "Bad Faith' Refusal to Settle by Liability Insurers: Some Implications of the Judgment-Proof Problem," Journal of Legal Studies, 23, 77-110. 
Yeon-Koo Che

Economics Department

Columbia University

420 West 118th Street

New York, NY 10027

E-mail: yc2271@columbia.edu

Kathryn E. Spier

Harvard Law School

1563 Massachusetts Avenue

Cambridge, MA 02138

E-mail: kspier@law.harvard.edu 